\title{
Denitrification in a closed rotating biological contactor: effect of disk submergence
}

\author{
Pilar Teixeira, Rosário Oliveira * \\ Centro de Engenharia Biológica-IBQF, Universidade do Minho, Campus de Gualtar, 4709 Braga Codex, Portugal
}

Received 7 March 2001; received in revised form 6 April 2001; accepted 17 May 2001

\begin{abstract}
Several studies have employed rotating biological contactors (RBCs) for nitrogen removal. However, partially submersed disks are used for nitrification, while completely submersed disks are used for denitrification. The objective of this study was to investigate the effect of disk submergence in the performance of rotating biological contactors, in terms of the denitrification process. Two RBCs, one with completely submersed disks (100\% submergence) and the other with partially submersed disks $(64.5 \%)$, were operated under the same conditions. Their performance was evaluated in terms of denitrification efficiency as well as biofilm characteristics, composition and activity. As far as the denitrification process is concerned, the RBC with a completely submersed biofilm was more efficient than the other but had a longer delay in start-up. The biofilm of both reactors was very thick $(>0.6 \mathrm{~mm}$ ), but with different structures. Biofilm activity seems to be directly dependent on the biofilm structure, namely on the degree of hydration. (C) 2001 Elsevier Science Ltd. All rights reserved.
\end{abstract}

Keywords: Denitrification; Rotating biological contactor; Disks submergence; Biofilm activity; Biofilm composition

\section{Introduction}

Biological denitrification is the most widely used method for removing nitrogen compounds from wastewaters. In this process, nitrate is reduced via nitrite to nitrous oxide and finally to nitrogen gas by facultative heterotrophic bacteria. The conventional technologies used for biological nitrogen removal are activated sludge systems, oxidation ditches and sequencing batch reactors [1]. The use of a closed rotating biological contactor is a relatively new biological wastewater treatment process. It combines advantages of the aerobic rotating biological contactor (high biomass concentration, short hydraulic retention time, low energy consumption, operational simplicity) and the anaerobic process (low quantities of waste biological solids) [2]. In this type of reactor, the formation of a stable biofilm (which is crucial for a good per-

\footnotetext{
* Corresponding author. Tel.: + 351-253-604-409; fax: + 351-253678-986

E-mail address: roliveira@deb.uminho.pt (R. Oliveira).
}

formance) is influenced by parameters such as substrate loading rate, hydraulic retention time, number of stages, disk rotational speed and disk submergence. Friedman [3], working with an eight stage RBC, with $38 \%$ disk submergence, verified that disk rotational speed significantly affects reactor performance. $\mathrm{Lu}$ and co-workers [2] also investigated the effect of disk rotational speed and the effect of submergence on the performance of an anaerobic RBC for COD removal. They concluded that the reactor has more mixed conditions when operated at higher disk rotational speed or at lower disk submergence. These authors also consider that extensive process design information with respect to disk submergence is still not available in the literature. Several studies have employed rotating biological contactors for nitrogen removal [4-8]. However, partially submerged disks are used for nitrification, while completely submerged disks are used for denitrification.

The purpose of this study was to investigate the effect of disk submergence in rotating biological contactors performance, in terms of the denitrification process. 


\section{Materials and methods}

\subsection{Experimental apparatus}

Two closed rotating biological contactors were used with completely $(100 \%)$ and partially $(64.5 \%)$ immersed disks, $\mathrm{RBC1}$ and $\mathrm{RBC} 2$, respectively. The $\mathrm{RBC1}$ consisted of two stages, each one contained seven polymethylmethacrylate disks of $16.2 \mathrm{~cm}$ diameter and $2 \mathrm{~cm}$ spacing between disks. Each stage was separated by a fixed baffle that contained three holes (diameter $=2$ $\mathrm{cm}$ ) and an angle of $30^{\circ}$ between them in order to allow wastewater passage without short-circuiting. The RBC2 was a single stage system consisting of 13 poly-methylmethacrylate disks (diameter $=23.4 \mathrm{~cm}$ ) mounted in a rotating shaft. Both reactors were operated with a hydraulic retention time of $2 \mathrm{~h}$, a rotational speed of 2 $\mathrm{rpm}$ and a temperature maintained at $26^{\circ} \mathrm{C}$ by means of a water jacket. The design characteristics of the RBCs are listed in Table 1.

\subsection{Start-up of the RBCs}

Cultures of Alcaligenes denitrificans ATCC 15173 were grown in batch mode for 3 days at $26{ }^{\circ} \mathrm{C}$ in an orbital shaker at $150 \mathrm{rpm}$. The reactors were inoculated with $600 \mathrm{ml}$ of these cultures. For the initial formation and accumulation of biofilm, the reactors were operated in batch mode for a week. After this period, they were fed continuously with a synthetic wastewater: 408 $\mathrm{mg} / 1 \mathrm{C}_{6} \mathrm{H}_{5} \mathrm{Na}_{3} \mathrm{O}_{7} \cdot 2 \mathrm{H}_{2} \mathrm{O}, 360.9 \mathrm{mg} / 1 \mathrm{KNO}_{3}, 93 \mathrm{mg} / 1$ $\mathrm{K}_{2} \mathrm{HPO}_{4}, 18 \mathrm{mg} / 1 \mathrm{KH}_{2} \mathrm{PO}_{4}, 24.2 \mathrm{mg} / 1 \mathrm{NaMoO}_{4} \cdot 2 \mathrm{H}_{2} \mathrm{O}$, $5.6 \mathrm{mg} / 1 \mathrm{FeSO}_{4} \cdot 7 \mathrm{H}_{2} \mathrm{O}, 0.81 \mathrm{mg} / 1 \mathrm{MnCl}_{2} \cdot 2 \mathrm{H}_{2} \mathrm{O}, 51.5$ $\mathrm{mg} / 1 \mathrm{CaCl}_{2} \cdot 2 \mathrm{H}_{2} \mathrm{O}$ and $409.2 \mathrm{mg} / 1 \mathrm{MgSO}_{4} \cdot 7 \mathrm{H}_{2} \mathrm{O}$. Due to the medium buffering capacity, no $\mathrm{pH}$ adjustment was performed. This medium had a ratio $\mathrm{C} / \mathrm{N}=2$, which is slightly higher than the theoretical value of 1.86. This last value is obtained considering the approach of McCarty et al. [9], taking the synthesis of bacterial cells into consideration. However, it is also necessary to consider that some carbon will be used for the deoxygenation of the medium.

Table 1

Characteristics of the closed rotating biological contactors

\begin{tabular}{lcc}
\hline & $\mathrm{RBC} 1$ & $\mathrm{RBC} 2$ \\
\hline Disk submergence (\%) & 100 & 64.5 \\
Number of stages & 2 & 1 \\
Disks per stage & 7 & 13 \\
Disk diameter $(\mathrm{cm})$ & 16.2 & 23.4 \\
Disk thickness $(\mathrm{mm})$ & 3.0 & 3.0 \\
Spacing between disks $(\mathrm{cm})$ & 2 & 2 \\
Surface area of disks $\left(\mathrm{m}^{2}\right)$ & 0.58 & 1.12 \\
Liquid volume $(\mathrm{l})$ & 16.4 & 13.0 \\
\hline
\end{tabular}

\subsection{Experimental}

During the course of continuous operation, parameters such as $\mathrm{pH}$, temperature, dissolved oxygen (DO), biomass concentration, total and volatile solids, nitrate, nitrite and citrate concentration, were measured. For the determination of nitrite, nitrate and citrate ions, the sample was filtered through a $0.2 \mu \mathrm{m}$ membrane filter in order to remove interfering suspended particles.

\subsection{Analytical methods}

Citrate and nitrate concentrations were measured by HPLC with an organic acid column (Chrompack, $300 \times 6.5 \mathrm{~mm}$ ). Nitrite was determined by a colorimetric method using $N$-(1-naphthyl)-ethylene-diamine, according to the Standard Methods of Analysis [10]. The total solids (TS), total volatile solids, $\mathrm{pH}$ and DO were determined also in accordance with the Standard Methods of Analysis. In order to separate the polymeric matrix from the cells, portions of biofilm from the first, middle and last disks of each reactor were submitted to an extraction procedure, according to the method of Azeredo et al. [11]. The protein content was determined by the Lowry modified method, using the protein assay kit SIGMA P5656 with a standard of bovine serum albumin (BSA). The polysaccharides were estimated colorimetrically by means of the phenol-sulphuric acid method of Dubois et al. [12], using glucose as standard. The biofilm thickness was measured with a Vernier calliper. The density was calculated in terms of dry mass per unit of wet volume and the procedure was as follows. A known portion of biofilm was inserted into a $10 \mathrm{ml}$ graduated cylinder partially filled with distilled water. The liquid volume displaced was measured. The mass of biofilm was converted in total solids.

\subsection{Biofilm activity}

The assessment of biofilm activity was performed by inoculating $90 \mathrm{ml}$ of the feeding medium, in $160 \mathrm{ml}$ flasks, with a known amount of biofilm. The biofilm samples to be used as inocula were removed from the first, middle and last disks, in order to evaluate the activity along the reactors. All the assays were duplicated. The flasks were incubated in an orbital shaker, at $26{ }^{\circ} \mathrm{C}$ and $150 \mathrm{rpm}$. The consumption of substrate (nitrate and citrate) as well as the nitrite concentration was followed along the time.

\section{Results and discussion}

\subsection{RBCs performance}

The reactors were operated for a period of 40 days. 


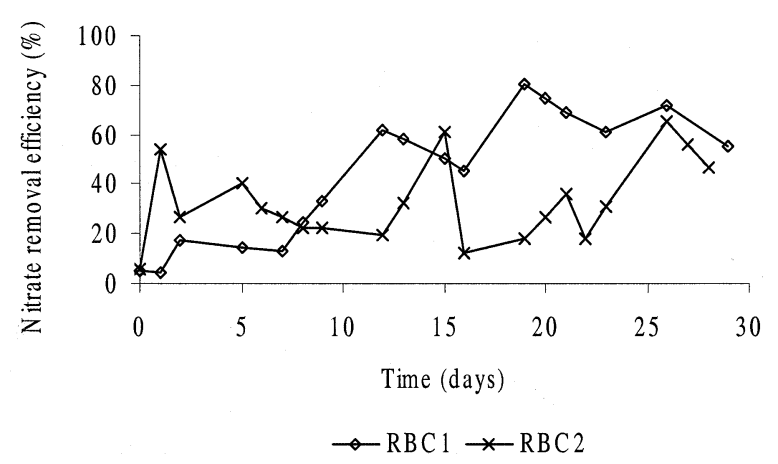

Fig. 1. Denitrification efficiency in RBC1 (100\% submergence) and in RBC2 (64.5\%).

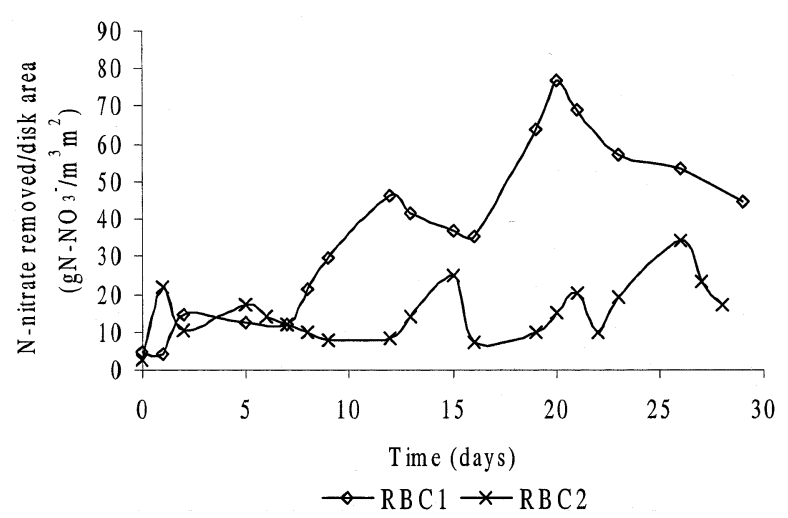

Fig. 2. Denitrification efficiency per total disk area in $\mathrm{RBC} 1(100 \%$ submergence) and in $\mathrm{RBC} 2(64.5 \%)$.

However, the day zero of monitoring corresponds to the day 10 of continuous operation. This time lag was allowed for biofilm formation and stabilization. In $\mathrm{RBC1}$, after 7 days, biomass growth was coincident with the depletion of dissolved oxygen. In day 9, the concentration of dissolved oxygen fell to zero and remained at this value until the end of the run. In the effluent, the $\mathrm{pH}$ was always between 6.9 and 7.5. Temperature within the reactor was around $26{ }^{\circ} \mathrm{C}$. In $\mathrm{RBC} 2$ the dissolved oxygen concentration was always zero (since the beginning of monitorization). The $\mathrm{pH}$ was in the range 7.1-7.9 and the temperature was $26{ }^{\circ} \mathrm{C}$. In both reactors, the $\mathrm{pH}$ of the effluent was higher than the $\mathrm{pH}$ of the influent, due to the production of alkalinity. Citrate was not completely consumed indicating that the carbon/nitrogen ratio of 2 was sufficient. The nitrate removal efficiency (\%) of both reactors is shown in Fig. 1. In the first 8 days, RBC2 with $64.5 \%$ of disks submergence removed more nitrate than RBC1, with completely submerged biofilm. After this period, $\mathrm{RBC} 1$ achieved almost $80 \%$ while $\mathrm{RBC} 2$ attained only a maximum of $57 \%$. These results seem to indicate that the completely submersed biofilm required more time to start-up. As A. denitrificans is considered an aerobic (facultative) denitrifier a faster development of biofilm can be expected in the reactor where the disks are exposed to higher oxygen concentration (RBC2). This was due to direct contact of the non-immersed forming biofilm with the air remaining in the headspace of the reactors during the first days of operation. In order to normalize the results, the $N$-nitrate removed was expressed per total area of disks (Fig. 2). After 7 days of operation, the $N$-nitrate removed/total disk area was always higher in $\mathrm{RBC} 1$, achieving a maximum of 77.0 gN-NO${ }_{3}^{-}$per $\mathrm{m}^{3} \mathrm{~m}^{2}$ and an average value of $36.71 \mathrm{gN}^{-\mathrm{NO}_{3}^{-}}$per $\mathrm{m}^{3} \mathrm{~m}^{2}$. The maximum obtained in $\mathrm{RBC} 2$ was only $37.77 \mathrm{gN}^{-\mathrm{NO}_{3}^{-}}$per $\mathrm{m}^{3} \mathrm{~m}^{2}$ with an average value of $16.97 \mathrm{gN}^{-N^{-}}$per $\mathrm{m}^{3}$ $\mathrm{m}^{2}$.

\subsection{Biofilm performance}

In order to maintain a stable biofilm, which is a key factor for the reactor performance, it is important to know the physical properties, composition and activity of biofilm.

\subsubsection{Physical characteristics of biofilm}

The aspect of the biofilms formed in $\mathrm{RBCl}$ and $\mathrm{RBC} 2$ is presented in Fig. 3a and b, respectively. The completely submersed biofilm was homogeneous, light yellow over the entire surface and with a similar thick-
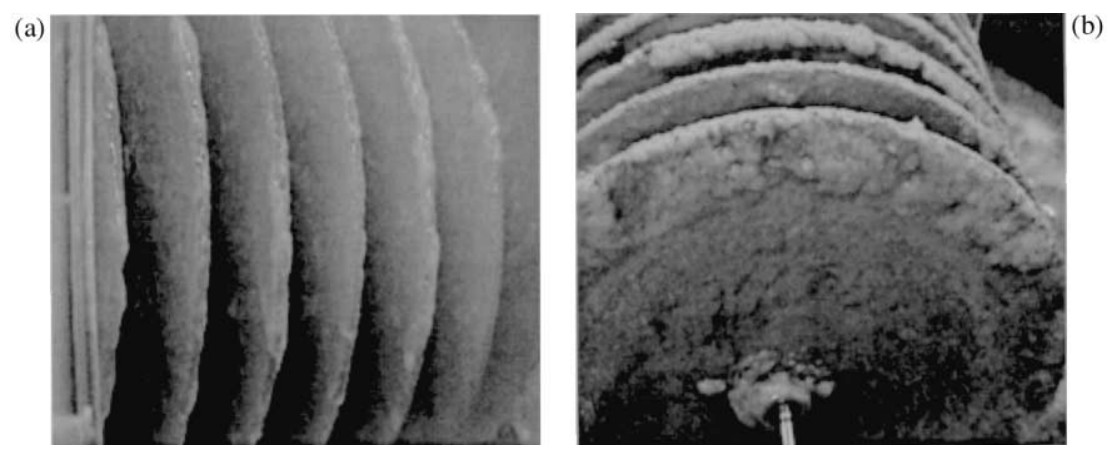

Fig. 3. (a) Biofilm completely submersed (RBC1). (b) Biofilm with $64.5 \%$ of submergence (RBC2). 
Table 2

Physical properties of completely and partially submerged biofilm

\begin{tabular}{|c|c|c|c|c|c|c|c|c|}
\hline \multirow[t]{2}{*}{ Disk } & \multicolumn{2}{|c|}{ Thickness (mm) } & \multicolumn{2}{|c|}{ Density (gTS/1) } & \multicolumn{2}{|l|}{ WW/DW } & \multicolumn{2}{|l|}{$\%$ Water } \\
\hline & $\mathrm{RBC1}$ & $\mathrm{RBC} 2$ & $\mathrm{RBC1}$ & $\mathrm{RBC} 2$ & $\mathrm{RBC1}$ & $\mathrm{RBC} 2$ & $\mathrm{RBC1}$ & $\mathrm{RBC} 2$ \\
\hline First & $1.9 \pm 1.2$ & $2.4 \pm 1.3$ & $10.2 \pm 1.2$ & $24.8 \pm 1.1$ & $80.4 \pm 9.6$ & $35.1 \pm 1.9$ & $98.7 \pm 0.2$ & $97.2 \pm 0.2$ \\
\hline Middle & $0.6 \pm 0.2$ & $1.4 \pm 0.5$ & $23.6 \pm 5.1$ & $34.0 \pm 8.1$ & $43.7 \pm 2.0$ & $32.7 \pm 8.9$ & $97.7 \pm 0.1$ & $96.8 \pm 0.9$ \\
\hline Last & $1.1 \pm 0.3$ & $1.2 \pm 0.2$ & $25.1 \pm 4.2$ & $28.0 \pm 2.7$ & $37.6 \pm 5.9$ & $39.2 \pm 8.1$ & $97.3 \pm 0.4$ & $97.0 \pm 0.2$ \\
\hline
\end{tabular}

Table 3

Composition of the polymeric matrices and mass of cells of the completely and of the partially submersed biofilms

\begin{tabular}{|c|c|c|c|c|c|c|c|c|}
\hline \multirow[t]{2}{*}{ Disk } & \multicolumn{2}{|c|}{ Cellular mass (gP/gTS) } & \multicolumn{2}{|c|}{ Protein (mg/gTS) } & \multicolumn{2}{|c|}{ Polysaccharides (mg/gTS) } & \multicolumn{2}{|c|}{ EPS (mg/gTS) } \\
\hline & $\mathrm{RBC} 1$ & $\mathrm{RBC} 2$ & $\mathrm{RBC1}$ & $\mathrm{RBC} 2$ & $\mathrm{RBC} 1$ & $\mathrm{RBC} 2$ & $\mathrm{RBC1}$ & $\mathrm{RBC} 2$ \\
\hline First & $0.67 \pm 0.03$ & $0.65 \pm 0.09$ & $10.65 \pm 2.4$ & $7.92 \pm 0.5$ & $59.05 \pm 5.1$ & $34.62 \pm 4.0$ & 69.7 & 42.5 \\
\hline Middle & $0.83 \pm 0.03$ & $0.90 \pm 0.02$ & $8.65 \pm 0.3$ & $10.76 \pm 0.1$ & $36.31 \pm 6.0$ & $46.05 \pm 3.0$ & 45.0 & 56.8 \\
\hline Last & $0.74 \pm 0.01$ & $1.27 \pm 0.19$ & $13.60 \pm 2.3$ & $11.08 \pm 0.6$ & $49.46 \pm 5.4$ & $36.27 \pm 5.6$ & 63.1 & 47.4 \\
\hline
\end{tabular}

ness over an entire disk. The biofilm of RBC2 $(64.5 \%$ of disk submergence) was darker in the non-immersed part and light yellow in the submersed zone. The physical characteristics were estimated as thickness, density or mass and are summarized in Table 2. All these biofilms were very thick $(>0.6 \mathrm{~mm})$, which is characteristic of many wastewaters treatment biofilm systems [13] and they are all highly hydrated. The partially submersed biofilm was always thicker and denser. This is in accordance with the lowest degree of hydration given by the ratio between the wet weight and the dry weight of biofilm (WW/DW) and \% water.

\subsubsection{Composition of biofilm}

Biofilms are formed by bacterial cells embedded in a polymeric matrix. The main constituents of the matrix are polysaccharides and proteins. Cellular mass is indirectly quantified by the total protein content minus the amount of protein present in the matrix. Assuming that the matrix was totally extracted, its composition is presented in Table 3. Extracellular polymeric substances (EPS) are the sum of the protein and polysaccharide content of the matrix. This sum can only be considered in comparative terms, on account of the standards used in quantification, which do not allow the expression of absolute values. The amount of cells in $\mathrm{RBC} 1$ was higher in the middle disk and lower in the first one. In $\mathrm{RBC} 2$, it increased from the inlet to the outlet of the reactor. Generally, the polymeric matrix was more developed in RBC1, especially in the first disk. In RBC2, the higher EPS content was found in the middle disk biofilm.

\subsubsection{Biofilm activity}

The activity of the biofilm portions removed from first, middle and last disks in both reactors is expressed as nitrate uptake rate (Fig. 4). As can be observed in Fig. 4, the activity of RBC1 biofilm was always higher than in $\mathrm{RBC} 2$. In the first disk, this value was considerably higher than in the other disks, where the activity was approximately the same. This should be expected due to the higher substrate concentration in the inlet zone. Fig. 5 shows the maximum production rate and uptake rate of nitrite. It can be observed that, generally, nitrite production and its consumption were higher in $\mathrm{RBC} 1$. They are more pronounced in the first disk of both reactors, which is in accordance with the specific activity in terms of nitrate removal. It must be noted that in this case thicker biofilms were the most active. According to Zhang and Bishop [14], as the biofilm becomes thicker, both the internal mass transfer resistance and substrate transformation limit the aerobic

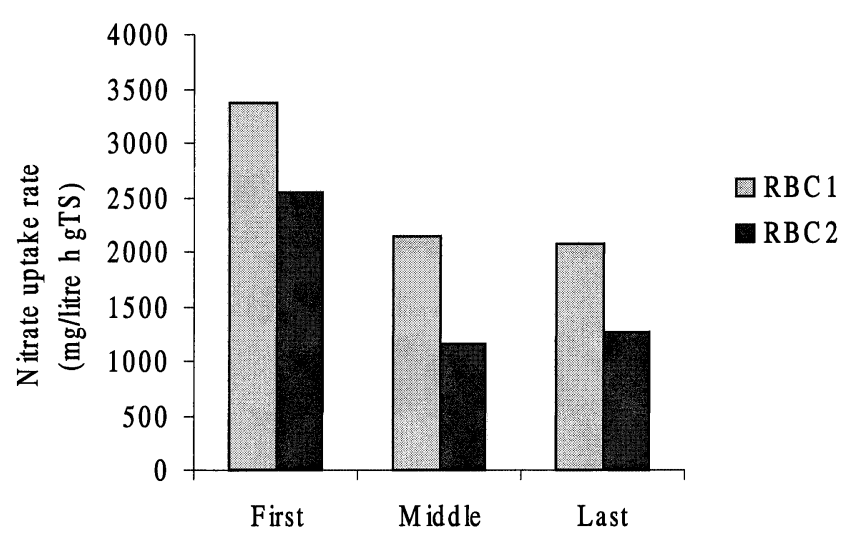

Fig. 4. Maximum specific activity rate of nitrate consumption of biofilm of $\mathrm{RBC} 1$ and $\mathrm{RBC} 2$. 


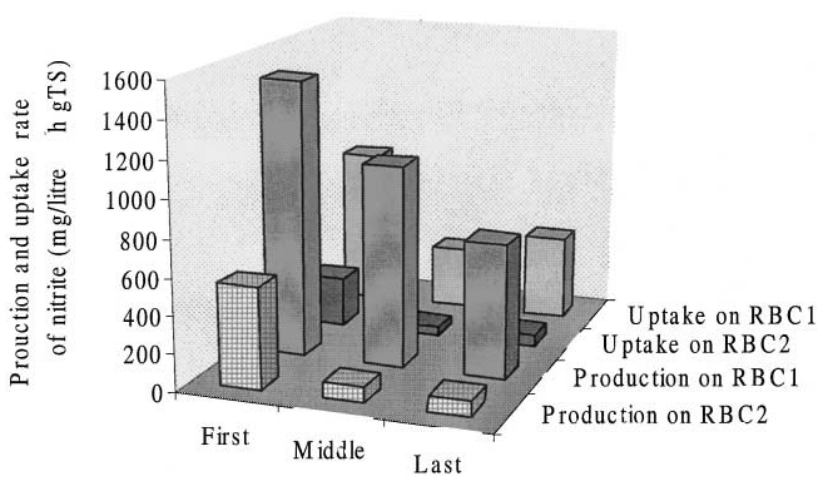

Fig. 5. Maximum specific activity rate of nitrite production and nitrite consumption of biofilm in both reactors.

bacteria growth. However, in the present situation the denitrification process is anoxic and depletion of oxygen is not a limiting factor. Moreover, it has been reported that some biofilms have a heterogeneous structure consisting of cell clusters separated by channels [15]. These channels may allow liquid flow inside biofilm [16]. Thus, for the highly hydrated biofilms under consideration, the presence of water channels may facilitate the substrate transport through biofilms, enabling cell activity along biofilm depth. Regarding the biofilm composition, in $\mathrm{RBC} 1$ the cellular biomass, expressed as mass of protein per mass of total solids $(\mathrm{gP} / \mathrm{gTS})$, was lower in the first disk. However, this biofilm was more active in terms of substrate removal, which can be explained by the higher substrate concentration in the inlet zone together with the presence of water channels favoring nutrient transport to the cells. Thus, in spite of the lower amount of cells they are all strongly active. The RBC2 first disk followed the same behavior as the $\mathrm{RBC} 1$ first disk. The decrease in the substrate removal activity along the other disks in both reactors is probably related with the increase in mass resistance on account of less hydration and mainly due to the existence of a higher degree of cell lysis. The biofilm samples assayed were 40-days-old and those from disks near the outlet were subjected to a lower nutrient concentration, which could be responsible for a pronounced aging of biofilm. It must be noted that the amount of cells is expressed in terms of protein content and some could be due to cell lysis. All this reasoning is corroborated by the dark color of the biofilm in the last disks of both reactors, being more marked in $\mathrm{RBC} 2$.

\section{Conclusions}

The $\mathrm{RBC1}$ reactor with the completely submersed disks proved to be more efficient in terms of the denitrification process. Nevertheless, it had a longer startup, which delayed the attainment of maximum efficiency.
The RBC1 biofilm is thinner, less dense and more hydrated than the partially submersed biofilm. These characteristics reduce the limitations of internal mass transfer.

\section{Acknowledgements}

The authors fully acknowledge the financial support provided by Instituto de Biotecnologia e Química Fina (IBQF) and PRAXIS XXI through grant BD/9121/96.

\section{References}

[1] Kornaros M, Lyberatos G. Kinetics of aerobic growth of a denitrifying bacterium, Pseudomonas denitrificans, in the presence of nitrates and/or nitrites. Water Res 1997;31(3):479-88.

[2] Lu C, Li HC, Lee LY. Effects of disc rotational speed and submergence on the performance of an anaerobic rotating biological contactor. Environ Int 1997;23(2):253-63.

[3] Friedman AA. Effect of disk rotational speed on biological contactor efficiency. J Water Pollut Control Fed 1979;51(11):2678-90.

[4] Pano A, Middlebrooks EJ. Kinetics of carbon and ammonia nitrogen removal in RBCs. J Water Pollut Control Fed 1983;55(7):956-65.

[5] Watanabe Y, Masuda S, Ishiguro M. Simultaneous nitrification and denitrification in micro-aerobic biofilms. Water Sci Tech 1992;26(3/4):511-22.

[6] Watanabe Y, Bang DY, Itoh K, Matsui K. Nitrogen removal from wastewaters by a bio-reactor with partially and fully submerged rotating biofilms. Water Sci Tech 1994;29(10/11):431-8.

[7] Gupta SK, Raja SM, Gupta AB. Simultaneous nitrification-denitrification in a rotating biological contactor. Environ Technol 1994; 15:145-53.

[8] Bang DY, Watanabe Y, Noike T. An experimental study on aerobic denitrification with polyvinyl alcohol as a carbon source in biofilms. Water Sci Tech 1995;32(8):235-42.

[9] McCarty PL, Beck L, Amant PS. Biological denitrification of wastewaters by addition of organic materials. In: Proceedings of the twenty fourth Industrial Waste Conference, Purdue University, West Layfayette, Indiana, 1969, p. 1271-1285.

[10] APHA. Standard Methods for the Examination of Water and Wastewater. 18th ed. American Public Health Association Inc., Washington DC, USA, 1992.

[11] Azeredo J, Oliveira R, Lazarova V. A new method for extraction of exopolymers from activated sludges. Water Sci Tech 1998;37(4/5):367-70.

[12] Dubois M, Gilles KA, Hamilton JK, Rebers PA, Smith F. Colorimetric method for determination of suggars and related substances. Anal Chem 1956;28(3):350-5.

[13] Bishop PL. Biofilm structure and kinetics. In: Proceedings of the Third International IAWQ Special Conference on Biofilm Systems, Copenhagen, 1996.

[14] Zhang T, Bishop PL. Structure, activity and composition of biofilms. Water Sci Tech 1994;29(7):335-44.

[15] de Beer D, Stoodley P, Roe F, Lewandowski Z. Effects of biofilm structure on oxygen distribution and mass transport. Biotechnol Bioeng 1994;43(11):1131-8.

[16] Stoodley P, de Beer D, Lewandowski Z. Liquid flow in biofilm systems. Appl Environ Microbiol 1994;60(8):2711-6. 